\title{
UDC 517.9
}

\author{
R. M. Tatsij, O. Yu. Chmyr, O. O. Karabyn \\ Lviv State University of Life Safety
}

\section{THE TOTAL FIRST BOUNDARY VALUE PROBLEM FOR EQUATION OF HYPERBOLIC TYPE WITH PIECEWISE CONSTANT COEFFICIENTS AND $\delta$-SINGULARITIES}

\begin{abstract}
For the first time a new formal solving scheme of the general first boundary value problem for a hyperbolic type equation with piecewise constant coefficients and $\delta$-singularities was proposed and justified. In the basis of the solving scheme is a concept of quasi-derivatives, a modern theory of systems of linear differential equations, the classical Fourier method and a reduction method. The advantage of this method is a possibility to examine a problem on each breakdown segment and then to combine obtained solutions on the basis of matrix calculation. Such an approach allows the use of software tools for solving the problem.

$M S C: 34 B 05$.

Key words: quasi-differential equation, the boundary value problem, the Cauchy matrix, the Dirac function, the eigenvalues problem, the method of Fourier and the method of eigenfunctions.

DOI: 10.18524/2519-206x.2019.1(33).175549.
\end{abstract}

INTRODUCTION. Methods for solving nonstationary boundary value problems can be divided into direct methods which basis includes the separation of variables method, method of sources (Green's function method), method of integral transforms, approximate methods and numerical methods.

The scheme proposed in this article belongs to the direct methods for solving boundary value problems. In the basis of this scheme is the concept of quasiderivatives [10] that lets to bypass the problem of multiplication of generalized functions.

First of all a mixed problem for the heat equation with piecewise continuous coefficients by the general boundary conditions of the first kind [11] was solved.

The general boundary value problems for hyperbolic equation with piecewise continuous on spatial variable coefficients and right parts was considered in [7].

This article examines the general first boundary value problem for a hyperbolic type equation with piecewise constant coefficients and $\delta$ - singularities. With the use of the reduction method solving of such a problem is reduced to finding a solution of the stationary inhomogeneous boundary value problem with the initial boundary conditions and the mixed problem with the zero boundary conditions for an inhomogeneous equation.

\section{Main Results}

1. Main designations, formulation of the problem and supporting statements. Let $I$ be an open interval of the real axis $\mathbb{R},\left[x_{0} ; x_{n}\right] \subset I$ - segment of the real axis; $0=x_{0}<x_{1}<x_{2}<\ldots<x_{i-1}<x_{i}<x_{i+1} \ldots<x_{n-1}<x_{n}=l$ - arbitrary partition of the segment $\left[x_{0} ; x_{n}\right]$ of the real axis $O x$ into $n$ parts. 
Let's declare the main designations:

$\theta_{i}$ - characteristic function of the interval $\left[x_{i} ; x_{i+1}\right)$, that is $\theta_{i}(x)=\left\{\begin{array}{ll}1, & x \in\left[x_{i}, x_{i+1}\right), \\ 0, & x \notin\left[x_{i}, x_{i+1}\right),\end{array} \quad i=\overline{0, n-1}\right.$.

Remark 1. Let $a_{1 i}, a_{2 i}, i=\overline{0, n-1}$ be real numbers. If $a_{1}=\sum_{i=0}^{n-1} a_{1 i} \theta_{i}, a_{2}=$ $\sum_{i=0}^{n-1} a_{2 i} \theta_{i}$, then $a_{1} \cdot a_{2}=\sum_{i=0}^{n-1} a_{1 i} \cdot a_{2 i} \theta_{i}$. In particular, if $a=\sum_{i=0}^{n-1} a_{i} \theta_{i}$, then $\frac{1}{a}=$ $\sum_{i=0}^{n-1} a_{i}^{-1} \theta_{i}$

Let's declare $B V_{l o c}^{+}(I)$ as a class of continuous from the right functions, locally bounded on I variation [2].

Let $m_{i}, i=\overline{0, n-1}, M_{i}, i=\overline{1, n-1}, \lambda_{i}, i=\overline{0, n-1}$ be positive real numbers, $g_{i}$, $i=\overline{0, n-1}, s_{i}, i=\overline{1, n-1}$ - real numbers and $\delta_{i}=\delta_{i}\left(x-x_{i}\right)-\delta$ - Dirac's function with a carrier at the point $x=x_{i} \in I$. Let's define

$m(x)=\sum_{i=0}^{n-1} m_{i} \theta_{i}+\sum_{i=1}^{n-1} M_{i} \delta\left(x-x_{i}\right) ; \lambda(x)=\sum_{i=0}^{n-1} \lambda_{i} \theta_{i} ;$

$f(x)=g(x)+s(x)=\sum_{i=0}^{n-1} g_{i} \theta_{i}+\sum_{i=1}^{n-1} s_{i} \delta_{i}\left(x-x_{i}\right)$.

Note that if $M(x)$ is an antiderivative for $m(x)$, then $m(x) \stackrel{\text { def }}{=} M^{\prime}(x)$. We assume here, that the function $M(x)$ is extended arbitrarily (for example, zero) on the interval $I /\left[x_{0} ; x_{n}\right]$.

Let's examine the general first boundary value problem for a hyperbolic type equation

$$
m(x) \frac{\partial^{2} u}{\partial t^{2}}=\frac{\partial}{\partial x}\left(\lambda(x) \frac{\partial u}{\partial x}\right)+f(x), \quad x \in\left(x_{0} ; x_{n}\right), \quad t \in(0 ;+\infty),
$$

with the boundary conditions

$$
\left\{\begin{array}{l}
u\left(x_{0}, t\right)=\psi_{0}(t), \\
u\left(x_{n}, t\right)=\psi_{n}(t),
\end{array} \quad t \in[0 ;+\infty)\right.
$$

and the initial conditions

$$
\left\{\begin{array}{l}
u(x, 0)=\varphi_{0}(x), \\
\frac{\partial u}{\partial t}(x, 0)=\varphi_{1}(x),
\end{array} \quad x \in\left[x_{0} ; x_{n}\right],\right.
$$

where $\psi_{0}(t), \psi_{n}(t) \in C^{2}(0 ;+\infty), \varphi_{0}(x), \varphi_{1}(x)$ are piecewise continuous on $\left(x_{0} ; x_{n}\right)$.

The method of reduction for finding a solution of the problem is described in detail in $[1,12]$ for example. In accordance with this method we can find a solution to the problem as a sum of two functions

$$
u(x, t)=w(x, t)+v(x, t) .
$$


Let's choose one of the functions for example $w(x, t)$ in a particular method, then the $v(x, t)$ function will be defined clearly.

2. Building the function $w(x, t)$. Let's define a function $w(x, t)$ as a solution of a boundary value problem

$$
\begin{gathered}
\left(\lambda(x) w_{x}{ }^{\prime}\right)_{x}{ }^{\prime}=-f(x) \\
\left\{\begin{array}{l}
w\left(x_{0}, t\right)=\psi_{0}(t), \\
w\left(x_{n}, t\right)=\psi_{n}(t),
\end{array} \quad t \in[0 ;+\infty) .\right.
\end{gathered}
$$

Note that a variable $t$ is considered as a parameter here.

In the basis of the solving method of the problem (5), (6) is the concept of quasiderivatives [9].

Let's introduce the vectors $\bar{W}=\left(\begin{array}{c}w \\ w^{[1]}\end{array}\right)$, where $w^{[1]}=\lambda w_{x}{ }^{\prime}, \bar{G}=\left(\begin{array}{c}0 \\ -g(x)\end{array}\right)$, $\bar{S}_{i}=\left(\begin{array}{c}0 \\ -s_{i}\end{array}\right), \bar{S}=\sum_{i=1}^{n-1} \bar{S}_{i} \cdot \delta_{i}$. Using these definitions, the quasi-differential equation (5) simplifies to the equivalent system of differential equations of the first order

$$
\bar{W}_{x}^{\prime}=\left(\begin{array}{cc}
0 & \frac{1}{\lambda(x)} \\
0 & 0
\end{array}\right) \cdot \bar{W}+\bar{G}+\bar{S}
$$

As a solution of the system (7) we take a vector function $\bar{W}(x, t)$ that belongs to the $B V_{l o c}^{+}(I)$ class by the $x$ variable and fulfills the system (7) in a generalized sense [9].

Boundary conditions (6) can be written down in vector form

$$
P \cdot \bar{W}\left(x_{0}, t\right)+Q \cdot \bar{W}\left(x_{n}, t\right)=\bar{\Gamma}(t),
$$

where $P=\left(\begin{array}{ll}1 & 0 \\ 0 & 0\end{array}\right), Q=\left(\begin{array}{ll}0 & 0 \\ 1 & 0\end{array}\right), \bar{\Gamma}(t)=\left(\begin{array}{l}\psi_{0}(t) \\ \psi_{n}(t)\end{array}\right)$.

Let $w_{i}(x, t), w_{i}^{[1]}(x, t)$ and $g_{i}(x)$ be defined on the interval $\left[x_{i} ; x_{i+1}\right)$. Let's define

$$
w(x, t)=\sum_{i=0}^{n-1} w_{i}(x, t) \theta_{i} .
$$

On the $\left[x_{i} ; x_{i+1}\right)$ interval the system $(7)$ is represented as

$$
\left(\begin{array}{c}
w_{i} \\
w_{i}^{[1]}
\end{array}\right)_{x}^{\prime}=\left(\begin{array}{cc}
0 & \frac{1}{\lambda_{i}} \\
0 & 0
\end{array}\right)\left(\begin{array}{c}
w_{i} \\
w_{i}^{[1]}
\end{array}\right)+\left(\begin{array}{c}
0 \\
-g_{i}
\end{array}\right)+\left(\begin{array}{c}
0 \\
-s_{i}
\end{array}\right)
$$

where $s_{0} \stackrel{\text { def }}{=} 0$. 
Let's examine a homogeneous system that corresponds to the system (10)

$$
\left(\begin{array}{c}
w_{i} \\
w_{i}^{[1]}
\end{array}\right)_{x}^{\prime}=\left(\begin{array}{cc}
0 & \frac{1}{\lambda_{i}} \\
0 & 0
\end{array}\right)\left(\begin{array}{c}
w_{i} \\
w_{i}^{[1]}
\end{array}\right)
$$

The Cauchy matrix $B_{i}(x, s)$ of such a system is represented as

$$
B_{i}(x, s)=\left(\begin{array}{cc}
1 & b_{i}(x, s) \\
0 & 1
\end{array}\right)
$$

where $b_{i}(x, s)=\int_{s}^{x} \frac{1}{\lambda_{i}} d z=\frac{x-s}{\lambda_{i}}$.

Let's define (for an arbitrary $k \geq i$ )

$$
B\left(x_{k}, x_{i}\right) \stackrel{\text { def }}{=} B_{k-1}\left(x_{k}, x_{k-1}\right) \cdot B_{k-2}\left(x_{k-1}, x_{k-2}\right) \cdot \ldots \cdot B_{i}\left(x_{i+1}, x_{i}\right) .
$$

The structure (11) of the matrices $B_{i}(x, s)$ allows us to define the structure of the matrix (12)

$$
B\left(x_{k}, x_{i}\right)=\left(\begin{array}{cc}
1 & \sum_{m=i}^{k-1} \frac{x_{m+1}-x_{m}}{\lambda_{m}} \\
0 & 1
\end{array}\right),
$$

besides that $B\left(x_{k}, x_{k}\right) \stackrel{\text { def }}{=} E$, where $E$ is an identity matrix.

The solution of the system (10) on the interval $\left[x_{i} ; x_{i+1}\right)$ is

$$
\begin{aligned}
\bar{W}_{i}(x, t) & =B_{i}\left(x, x_{i}\right) \cdot \bar{P}_{i}+\int_{x_{i}}^{x} B_{i}(x, s) \cdot \bar{G}_{i}(s) d s= \\
& =B_{i}\left(x, x_{i}\right) \cdot \bar{P}_{i}+\left(\begin{array}{c}
-g_{i} \frac{\left(x-x_{i}\right)^{2}}{2 \lambda_{i}} \\
-g_{i}\left(x-x_{i}\right)
\end{array}\right),
\end{aligned}
$$

where $\bar{P}_{i}$ is a yet unknown vector [11].

Similarly on the interval $\left[x_{i-1} ; x_{i}\right)$

$$
\begin{gathered}
\bar{W}_{i-1}(x, t)=B_{i-1}\left(x, x_{i-1}\right) \cdot \bar{P}_{i-1}+\int_{x_{i-1}}^{x} B_{i-1}(x, s) \cdot \bar{G}_{i-1}(s) d s= \\
=B_{i-1}\left(x, x_{i-1}\right) \cdot \bar{P}_{i-1}+\left(\begin{array}{c}
-g_{i-1} \frac{\left(x-x_{i-1}\right)^{2}}{2 \lambda_{i-1}} \\
-g_{i-1}\left(x-x_{i-1}\right)
\end{array}\right) .
\end{gathered}
$$

At the point $x=x_{i}$ the conjugation condition has to be fulfilled that is $\bar{W}_{i}\left(x_{i}, t\right)=\bar{W}_{i-1}\left(x_{i}, t\right)+\bar{S}_{i}[13]$. As a result we get a recurrence relation

$$
\bar{P}_{i}=B_{i-1}\left(x_{i}, x_{i-1}\right) \cdot \bar{P}_{i-1}+\int_{x_{i-1}}^{x_{i}} B_{i-1}\left(x_{i}, s\right) \cdot \bar{G}_{i-1}(s) d s+\bar{S}_{i} .
$$


By the method of mathematical induction from (14) the following is received

$$
\bar{P}_{i}=B\left(x_{i}, x_{0}\right) \cdot \bar{P}_{0}+\sum_{k=0}^{i} B\left(x_{i}, x_{k}\right) \bar{Z}_{k}
$$

where $\bar{Z}_{k}=\int_{x_{k-1}}^{x_{k}} B_{k-1}\left(x_{k}, s\right) \cdot \bar{G}_{k-1}(s) d s+\bar{S}_{k}=\left(\begin{array}{c}-g_{k-1} \frac{\left(x_{k}-x_{k-1}\right)^{2}}{2 \lambda_{k-1}} \\ -g_{k-1}\left(x_{k}-x_{k-1}\right)\end{array}\right)+\left(\begin{array}{c}0 \\ -s_{k}\end{array}\right)$, $k=\overline{1, n-1}$, note that $\bar{Z}_{0} \stackrel{\text { def }}{=} \overline{0}, \bar{S}_{n} \stackrel{\text { def }}{=} \overline{0} ; \bar{P}_{0}$ is the initial (unknown) vector.

In order to find $\bar{P}_{0}$ the boundary conditions (8) should be used, where we define $\bar{W}\left(x_{0}, t\right) \stackrel{\text { def }}{=} \bar{P}_{0}$,

$\bar{W}\left(x_{n}, t\right) \stackrel{d e f}{=} \bar{W}_{n-1}\left(x_{n}, t\right)=B_{n-1}\left(x_{n}, x_{n-1}\right) \bar{P}_{n-1}+\int_{x_{n-1}}^{x_{n}} B_{n-1}\left(x_{n}, s\right) \cdot \bar{G}_{n-1}(s) d s=$

$=B_{n-1}\left(x_{n}, x_{n-1}\right) B\left(x_{n-1}, x_{0}\right) \bar{P}_{0}+B_{n-1}\left(x_{n}, x_{n-1}\right) \sum_{k=1}^{n-1} B\left(x_{n-1}, x_{k}\right) \bar{Z}_{k}+$

$+\int_{x_{n-1}}^{x_{n}} B_{n-1}\left(x_{n}, s\right) \cdot \bar{G}_{n-1}(s) d s=B\left(x_{n}, x_{0}\right) \bar{P}_{0}+\sum_{k=1}^{n} B\left(x_{n}, x_{k}\right) \bar{Z}_{k}$.

Then $\left[P+Q B\left(x_{n}, x_{0}\right)\right] \bar{P}_{0}+Q \sum_{k=1}^{n} B\left(x_{n}, x_{k}\right) \bar{Z}_{k}=\bar{\Gamma}$, and as a result

$$
\bar{P}_{0}=\left[P+Q \cdot B\left(x_{n}, x_{0}\right)\right]^{-1} \cdot\left(\bar{\Gamma}-Q \sum_{k=1}^{n} B\left(x_{n}, x_{k}\right) \bar{Z}_{k}\right) .
$$

Let's evaluate

$$
\begin{gathered}
{\left[P+Q \cdot B\left(x_{n}, x_{0}\right)\right]^{-1}=\left[\left(\begin{array}{ll}
1 & 0 \\
0 & 0
\end{array}\right)+\left(\begin{array}{ll}
0 & 0 \\
1 & 0
\end{array}\right) \cdot\left(\begin{array}{cc}
1 & \sum_{m=0}^{n-1} b_{m}\left(x_{m+1}, x_{m}\right) \\
0 & 1
\end{array}\right)\right]^{-1}=} \\
=\left(\begin{array}{cc}
1 & 0 \\
-\frac{1}{\sigma_{n}} & \frac{1}{\sigma_{n}}
\end{array}\right), \text { where } \sigma_{n}=\sum_{m=0}^{n-1} b_{m}\left(x_{m+1}, x_{m}\right)=\sum_{m=0}^{n-1} \frac{x_{m+1}-x_{m}}{\lambda_{m}}, \sigma_{0} \stackrel{\text { def }}{=} 0 \\
\bar{\Gamma}-Q \sum_{k=1}^{n} B\left(x_{n}, x_{k}\right) \bar{Z}_{k}=\left(\begin{array}{l}
\psi_{0}(t) \\
\psi_{n}(t)
\end{array}\right)-\left(\begin{array}{cc}
0 & 0 \\
1 & 0
\end{array}\right) \times \\
\times \sum_{k=1}^{n} B\left(x_{n}, x_{k}\right)\left(\int_{x_{k-1}}^{x_{k}} B_{k-1}\left(x_{k}, s\right) \cdot \bar{G}_{k-1}(s) d s+\bar{S}_{k}\right) .
\end{gathered}
$$

Let's write down the right side part (17) in a matrix form

$$
\begin{aligned}
& \int_{x_{k-1}}^{x_{k}} B_{k-1}\left(x_{k}, s\right) \cdot \bar{G}_{k-1}(s) d s+\bar{S}_{k}=\int_{x_{k-1}}^{x_{k}}\left(\begin{array}{cc}
1 & b_{k-1}\left(x_{k}, s\right) \\
0 & 1
\end{array}\right) \cdot\left(\begin{array}{c}
0 \\
-g_{k-1}
\end{array}\right) d s+ \\
& +\left(\begin{array}{c}
0 \\
-s_{k}
\end{array}\right)=\left(\begin{array}{c}
-\int_{x_{k-1}}^{x_{k}} b_{k-1}\left(x_{k}, s\right) \cdot g_{k-1} d s \\
-\int_{x_{k-1}}^{x_{k}} g_{k-1} d s-s_{k}
\end{array}\right) \stackrel{\operatorname{def}}{=}\left(\begin{array}{c}
I_{k-1}\left(x_{k}\right) \\
I_{k-1}^{[1]}\left(x_{k}\right)-s_{k}
\end{array}\right)=\bar{Z}_{k} ;
\end{aligned}
$$




$$
\begin{aligned}
& \sum_{k=1}^{n} B\left(x_{n}, x_{k}\right)\left(\begin{array}{c}
I_{k-1}\left(x_{k}\right) \\
I_{k-1}^{[1]}\left(x_{k}\right)-s_{k}
\end{array}\right)=\sum_{k=1}^{n}\left(\begin{array}{cc}
1 & \sum_{m=k}^{n-1} b_{m}\left(x_{m+1}, x_{m}\right) \\
0 & 1
\end{array}\right) \times \\
& \times\left(\begin{array}{c}
I_{k-1}\left(x_{k}\right) \\
I_{k-1}^{[1]}\left(x_{k}\right)-s_{k}
\end{array}\right)=\left(\begin{array}{c}
\sum_{k=1}^{n}\left(I_{k-1}\left(x_{k}\right)+\left(I_{k-1}^{[1]}\left(x_{k}\right)-s_{k}\right) \cdot \sum_{m=k}^{n-1} b_{m}\left(x_{m+1}, x_{m}\right)\right) \\
\sum_{k=1}^{n}\left(I_{k-1}^{[1]}\left(x_{k}\right)-s_{k}\right)
\end{array}\right) .
\end{aligned}
$$

Thus, we receive

$$
\begin{aligned}
& \bar{\Gamma}-Q \sum_{k=1}^{n} B\left(x_{n}, x_{k}\right) \bar{Z}_{k}=\left(\begin{array}{l}
\psi_{0}(t) \\
\psi_{n}(t)
\end{array}\right)-\left(\begin{array}{ll}
0 & 0 \\
1 & 0
\end{array}\right) \times \\
& \times\left(\begin{array}{c}
\sum_{k=1}^{n}\left(I_{k-1}\left(x_{k}\right)+\left(I_{k-1}^{[1]}\left(x_{k}\right)-s_{k}\right) \cdot \sum_{m=k}^{n-1} b_{m}\left(x_{m+1}, x_{m}\right)\right) \\
\sum_{k=1}^{n}\left(I_{k-1}^{[1]}\left(x_{k}\right)-s_{k}\right)
\end{array}\right)= \\
& =\left(\begin{array}{c}
\psi_{0}(t) \\
\psi_{n}(t)-\sum_{k=1}^{n}\left(I_{k-1}\left(x_{k}\right)+\left(I_{k-1}^{[1]}\left(x_{k}\right)-s_{k}\right) \cdot \sum_{m=k}^{n-1} b_{m}\left(x_{m+1}, x_{m}\right)\right)
\end{array}\right) .
\end{aligned}
$$

Let's substitute (18) to (16)

$$
\begin{gathered}
\bar{P}_{0}=\left(\begin{array}{cc}
1 & 0 \\
-\frac{1}{\sigma_{n}} & \frac{1}{\sigma_{n}}
\end{array}\right) \times \\
\times\left(\begin{array}{c}
\psi_{0}(t) \\
\psi_{n}(t)-\sum_{k=1}^{n}\left(I_{k-1}\left(x_{k}\right)+\left(I_{k-1}^{[1]}\left(x_{k}\right)-s_{k}\right) \cdot \sum_{m=k}^{n-1} b_{m}\left(x_{m+1}, x_{m}\right)\right)
\end{array}\right)= \\
=\left(\begin{array}{c}
\psi_{0}(t) \\
\left.\frac{\psi_{n}(t)-\psi_{0}(t)}{\sigma_{n}}-\frac{1}{\sigma_{n}} \sum_{k=1}^{n}\left(I_{k-1}\left(x_{k}\right)+\left(I_{k-1}^{[1]}\left(x_{k}\right)-s_{k}\right) \cdot \sum_{m=k}^{n-1} b_{m}\left(x_{m+1}, x_{m}\right)\right)\right)
\end{array}\right.
\end{gathered}
$$

Based on the formulas (13), (15), (19), after performed transformations an image of the vector function $\bar{W}_{i}(x, t)$ on the interval $\left[x_{i} ; x_{i+1}\right)$ is received

$$
\begin{aligned}
& \bar{W}_{i}(x, t)=B_{i}\left(x, x_{i}\right) \cdot\left(B\left(x_{i}, x_{0}\right) \cdot \bar{P}_{0}+\sum_{k=1}^{i} B\left(x_{i}, x_{k}\right) \bar{Z}_{k}\right)+\int_{x_{i}}^{x} B_{i}(x, s) \cdot \bar{G}_{i}(s) d s= \\
& =\left(\begin{array}{cc}
1 & b_{i}\left(x, x_{i}\right) \\
0 & 1
\end{array}\right) \cdot\left(\begin{array}{cc}
1 & \sigma_{i} \\
0 & 1
\end{array}\right) \cdot \bar{P}_{0}+\left(\begin{array}{cc}
1 & b_{i}\left(x, x_{i}\right) \\
0 & 1
\end{array}\right) \cdot \sum_{k=1}^{i}\left(\begin{array}{cc}
1 & \sum_{m=k}^{i-1} b_{m}\left(x_{m+1}, x_{m}\right) \\
0 & 1
\end{array}\right) \bar{Z}_{k}+
\end{aligned}
$$




$$
\begin{gathered}
+\int_{x_{i}}^{x}\left(\begin{array}{cc}
1 & b_{i}(x, s) \\
0 & 1
\end{array}\right) \cdot \bar{G}_{i}(s) d s=\left(\begin{array}{cc}
1 & b_{i}\left(x, x_{i}\right)+\sigma_{i} \\
0 & 1
\end{array}\right) \cdot \bar{P}_{0}+ \\
+\left(\begin{array}{cc}
1 & b_{i}\left(x, x_{i}\right) \\
0 & 1
\end{array}\right) \cdot\left(\begin{array}{c}
\sum_{k=1}^{i}\left(I_{k-1}\left(x_{k}\right)+\left(I_{k-1}^{[1]}\left(x_{k}\right)-s_{k}\right) \sum_{m=k}^{i-1} b_{m}\left(x_{m+1}, x_{m}\right)\right) \\
\sum_{k=1}^{i}\left(I_{k-1}^{[1]}\left(x_{k}\right)-s_{k}\right)
\end{array}\right)+ \\
+\left(\begin{array}{c}
-\int_{x_{i}}^{x} b_{i}(x, s) \cdot g_{i} d s \\
-\int_{x_{i}}^{x} g_{i} d s
\end{array}\right)=\left(\begin{array}{cc}
1 & b_{i}\left(x, x_{i}\right)+\sigma_{i} \\
0 & 1
\end{array}\right) \cdot \bar{P}_{0}+ \\
+\left(\begin{array}{c}
\sum_{k=1}^{i}\left(I_{k-1}\left(x_{k}\right)+\left(I_{k-1}^{[1]}\left(x_{k}\right)-s_{k}\right) \sum_{m=k}^{i-1} b_{m}\left(x_{m+1}, x_{m}\right)\right) \\
\sum_{k=1}^{i}\left(I_{k-1}^{[1]}\left(x_{k}\right)-s_{k}\right)+I_{i}^{[1]}(x)
\end{array}\right)+ \\
+\left(\begin{array}{c}
b_{i}\left(x, x_{i}\right) \sum_{k=1}^{i}\left(I_{k-1}^{[1]}\left(x_{k}\right)-s_{k}\right)+I_{i}(x) \\
0
\end{array}\right)
\end{gathered}
$$

The first coordinate of the vector $\bar{W}_{i}(x, t)$ in $(20)$ is indeed the searched function $w_{i}(x, t)$. Therefore

$$
\begin{gathered}
w_{i}(x, t)=\psi_{0}(t)+\left(b_{i}\left(x, x_{i}\right)+\sigma_{i}\right) \cdot \frac{\psi_{n}(t)-\psi_{0}(t)}{\sigma_{n}}-\frac{1}{\sigma_{n}}\left(b_{i}\left(x, x_{i}\right)+\sigma_{i}\right) \times \\
\times\left(\sum_{k=1}^{n}\left(I_{k-1}\left(x_{k}\right)+\left(I_{k-1}^{[1]}\left(x_{k}\right)-s_{k}\right) \sum_{m=k}^{n-1} b_{m}\left(x_{m+1}, x_{m}\right)\right)\right)+ \\
+\sum_{k=1}^{i}\left(I_{k-1}\left(x_{k}\right)+\left(I_{k-1}^{[1]}\left(x_{k}\right)-s_{k}\right) \sum_{m=k}^{i-1} b_{m}\left(x_{m+1}, x_{m}\right)\right)+ \\
+b_{i}\left(x, x_{i}\right) \sum_{k=1}^{i}\left(I_{k-1}^{[1]}\left(x_{k}\right)-s_{k}\right)+I_{i}(x) .
\end{gathered}
$$

By substituting the expression (21) into (9), the solution on the whole interval $\left[x_{0} ; x_{n}\right]$ is received.

3. Building the function $v(x, t)$.

Let's write down a mixed problem for the function $v(x, t)$. Substituting (4) into (1) and considering that the function $w(x, t)$ fulfills (5), an inhomogeneous equation is received

$$
m(x) \frac{\partial^{2} v}{\partial t^{2}}-\frac{\partial}{\partial x}\left(\lambda(x) \frac{\partial v}{\partial x}\right)=-m(x) \frac{\partial^{2} w}{\partial t^{2}}, \quad x \in\left(x_{0} ; x_{n}\right), \quad t \in(0 ;+\infty) .
$$


Let's substitute (4) into the initial conditions (3). Initial conditions for the function $v(x, t)$ are received

$$
\left\{\begin{array}{l}
v(x, 0)=\Phi_{0}(x), \\
\frac{\partial v}{\partial t}(x, 0)=\Phi_{1}(x),
\end{array} \quad x \in\left[x_{0} ; x_{n}\right],\right.
$$

where $\Phi_{0}(x) \stackrel{\text { def }}{=} \varphi_{0}(x)-w(x, 0), \Phi_{1}(x) \stackrel{\text { def }}{=} \varphi_{1}(x)-\frac{\partial w}{\partial t}(x, 0)$.

Since the function $w(x, t)$ fulfills the boundary conditions (6), then from (4) the boundary conditions for the function $v(x, t)$ will be the following

$$
\left\{\begin{array}{l}
v\left(x_{0}, t\right)=0, \\
v\left(x_{n}, t\right)=0,
\end{array} \quad t \in[0 ;+\infty) .\right.
$$

Therefore under the condition that the solution $w(x, t)$ of the problem (5), (6) is known, the function $v(x, t)$ is the solution of the mixed problem (22)-(24).

4. The Fourier method and the eigenvalue problem.

\subsection{Expansion by eigenfunctions.}

Let's examine the corresponding homogeneous equation for the equation (22)

$$
m(x) \frac{\partial^{2} v}{\partial t^{2}}=\frac{\partial}{\partial x}\left(\lambda(x) \frac{\partial v}{\partial x}\right) .
$$

Now let's find its nontrivial solutions

$$
v(x, t)=\sin (\omega t+\varepsilon) \cdot X(x),
$$

where $\omega$ is a parameter, $\varepsilon$ is a constant, $X(x)$ is a yet unknown function [1], that fulfill the boundary conditions (24).

Let's substitute (26) into the equation (25). Quasi-differential equation is received

$$
\left(\lambda(x) X^{\prime}(x)\right)^{\prime}+\omega^{2} m(x) X(x)=0 .
$$

Let's substitute (26) into the conditions (24). The following boundary conditions are received

$$
\begin{aligned}
& X\left(x_{0}\right)=0, \\
& X\left(x_{n}\right)=0 .
\end{aligned}
$$

As a solution of the equation (27) consider an absolutely continuous on the interval $\left[x_{0} ; x_{n}\right]$ function $X(x)$ that fulfills it in a generalized sense [9].

The problem $(27),(28)$ is the eigenvalue problem. The properties of the eigenvalues $\omega_{k}$ and the eigenfunctions of the problem (27), (28) are described in detail in [8]. In particular, it is established that all eigenvalues $\omega_{k}>0$ [5]; eigenfunctions $X_{k}\left(x, \omega_{k}\right)$ are orthogonal with the weight $m(x)=d M(x)$ :

$$
\int_{x_{0}}^{x_{n}} X_{i}\left(x, \omega_{i}\right) \cdot X_{j}\left(x, \omega_{j}\right) d M(x)=0, \quad i \neq j
$$




$$
\left\|X_{k}\right\|^{2}=\int_{x_{0}}^{x_{n}} X_{k}^{2}\left(x, \omega_{k}\right) d M(x) .
$$

If $F(x)$ is an absolutely continuous function that has different analytical expressions on each of the intervals $\left[x_{i} ; x_{i+1}\right)$, that is the function allows the image

$$
F(x)=\sum_{i=0}^{n-1} F_{i}(x) \cdot \theta_{i}
$$

on the interval $\left[x_{0} ; x_{n}\right]$, then its expansion by the eigenfunctions $X_{k}\left(x, \omega_{k}\right)$ is the following

$$
F(x)=\sum_{k=1}^{\infty} F_{k} \cdot X_{k}\left(x, \omega_{k}\right),
$$

where the Fourier coefficients $F_{k}$ are computed by the formulas

$$
F_{k}=\frac{1}{\left\|X_{k}\right\|^{2}} \cdot \int_{x_{0}}^{x_{n}} F(x) \cdot X_{k}\left(x, \omega_{k}\right) d M(x)
$$

Integration of the function $F(x)$ is performed as the Riemann-Stieltjes integral with respect to the $m(x)$,

$$
\int_{x_{0}}^{x_{n}} F(x) d M(x) \stackrel{\text { def }}{=} \sum_{i=0}^{n-1} m_{i} \int_{x_{i}}^{x_{i+1}} F_{i}(x) d x+\sum_{i=1}^{n-1} M_{i} \cdot F_{i}\left(x_{i}\right) .
$$

Functions of the type (30) are integrated the following way [9]: if

$$
F_{1}(x)=\sum_{i=0}^{n-1} F_{1 i}(x) \cdot \theta_{i}, \quad F_{2}(x)=\sum_{i=0}^{n-1} F_{2 i}(x) \cdot \theta_{i},
$$

then

$$
\begin{gathered}
\int_{x_{0}}^{x_{n}} F_{1}(x) \cdot F_{2}(x) d M(x)=\sum_{i=0}^{n-1} m_{1 i} \cdot m_{2 i} \int_{x_{i}}^{x_{i+1}} F_{1 i}(x) \cdot F_{2 i}(x) d x+ \\
+\sum_{i=1}^{n-1} M_{1 i} \cdot M_{2 i} \cdot F_{1 i}\left(x_{i}\right) \cdot F_{2 i}\left(x_{i}\right), \\
\left\|F_{k}\right\|^{2}=\int_{x_{0}}^{x_{n}} F_{k}^{2}(x) d M(x)=\sum_{i=0}^{n-1} m_{k i}^{2} \int_{x_{i}}^{x_{i+1}} F_{k i}^{2}(x) d x+ \\
+\sum_{i=1}^{n-1} M_{k i}^{2} \cdot F_{k i}^{2}\left(x_{i}\right), \quad k \geq 1 .
\end{gathered}
$$

The expression (32) is the dot product of the functions $F_{1}(x)$ and $F_{2}(x)$. The expression (33) is the norm square of the function $F_{k}(x)$. 
Let's define

$$
X_{k}\left(x, \omega_{k}\right)=\sum_{i=0}^{n-1} X_{k i}\left(x, \omega_{k}\right) \cdot \theta_{i} .
$$

Then for the Fourier coefficients $F_{k}$ and for the $X_{k}(x)$ from the (31) and (29) the following is received

$$
\begin{gathered}
F_{k}=\frac{1}{\left\|X_{k}\right\|^{2}}\left(\sum_{i=0}^{n-1} m_{i} \int_{x_{i}}^{x_{i+1}} F_{i}(x) \cdot X_{k i}\left(x, \omega_{k}\right) d x+\sum_{i=1}^{n-1} M_{i} \cdot F_{i}\left(x_{i}\right) \cdot X_{k i}\left(x_{i}, \omega_{k}\right)\right), \\
\left\|X_{k}\right\|^{2}=\sum_{i=0}^{n-1} m_{k i}^{2} \int_{x_{i}}^{x_{i+1}} X_{k i}^{2}\left(x, \omega_{k}\right) d x+\sum_{i=1}^{n-1} M_{k i}^{2} \cdot X_{k i}^{2}\left(x_{i}, \omega_{k}\right) .
\end{gathered}
$$

\subsection{Constructional approach to building eigenfunctions.}

Let's introduce a quasi-derivative $X^{[1]} \stackrel{\text { def }}{=} \lambda X^{\prime}$, a vector $\bar{X}=\left(\begin{array}{c}X \\ X^{[1]}\end{array}\right)$ and matrices $A_{k}=\left(\begin{array}{cc}0 & \frac{1}{\lambda_{k}} \\ -m_{k} \omega^{2} & 0\end{array}\right), C_{k}=\left(\begin{array}{cc}0 & 0 \\ -M_{k} \omega^{2} & 0\end{array}\right)$. Now let's reduce a quasi-differential equation (27) to the system of the first order differential equations

$$
\bar{X}^{\prime}=\left(\sum_{k=0}^{n-1} A_{k} \theta_{k}+\sum_{k=1}^{n-1} C_{k} \delta\left(x-x_{k}\right)\right) \cdot \bar{X} .
$$

Similarly to the paragraph 2.2 , the solution of the system (35) is considered to be a vector function $\bar{X}(x, \omega) \in B V_{l o c}^{+}(I)$ that fulfills it in a sense of the theory of generalized functions.

Let's write down the corresponding system on the interval $\left[x_{i}, x_{i+1}\right)$ in a following way

$$
\bar{X}_{i}^{\prime}=\left(A_{i}+C_{i} \delta_{i}\right) \cdot \bar{X}_{i}, \quad i=\overline{0, n-1} .
$$

It is known [9] that the jump of the system's solution at the point $x=x_{i}$ is $\Delta X_{i}\left(x_{i}\right)=C_{i} X_{i-1}\left(x_{i}\right)$.

This gives an opportunity to reduce the problem to the equivalent problem of the system of impulsive differential equations [6]

$$
\begin{gathered}
\bar{X}^{\prime}=\sum_{k=0}^{n-1} A_{k} \theta_{k} \cdot \bar{X}, \\
\bar{X}_{i}\left(x_{i}\right)-\bar{X}_{i-1}\left(x_{i}\right)=C_{i} \bar{X}_{i-1}\left(x_{i}\right)
\end{gathered}
$$

and the following boundary conditions

$$
P \bar{X}\left(x_{0}\right)+Q \bar{X}\left(x_{n}\right)=\overline{0} .
$$

The system is examined in detail in [9]. Let's note the main properties of the system: 
- this system is proper (namely, it is clearly defined in a sense of the theory of generalized functions), because the following condition is valid

$$
C_{k}^{2}=\left(\begin{array}{cc}
0 & 0 \\
-M_{k} \omega^{2} & 0
\end{array}\right)^{2}=\left(\begin{array}{ll}
0 & 0 \\
0 & 0
\end{array}\right)
$$

- the fundamental matrix (analog of the Cauchy matrix on the whole interval $\left[x_{0} ; x_{n}\right]$ ) has the following structure

$$
\widetilde{B}\left(x, x_{0}, \omega\right) \stackrel{\text { def }}{=} \sum_{i=0}^{n-1} \widetilde{B}_{i}\left(x, x_{i}, \omega\right) \cdot \widetilde{B}\left(x_{i}, x_{0}, \omega\right) \cdot \theta_{i}
$$

where $\widetilde{B}\left(x_{i}, x_{0}, \omega\right) \stackrel{\text { def }}{=} \prod_{j=0}^{i} \widetilde{C}_{j} \cdot \widetilde{B}_{i-j}\left(x_{i-j+1}, x_{i-j}, \omega\right), \widetilde{C}_{i}=\left(E+C_{i}\right), i=\overline{1, n-1}$, $\widetilde{B}\left(x_{i}, x_{i}, \omega\right) \stackrel{\text { def }}{=} E$.

With a direct verification let's ascertain that the Cauchy matrix $\widetilde{B}_{i}(x, s, \omega)$ of the system (36) on the interval $\left[x_{i} ; x_{i+1}\right)$ is the following $\widetilde{B}_{i}(x, s, \omega)=\left(\begin{array}{cc}\cos \alpha_{i}(x-s) & \frac{\sin \alpha_{i}(x-s)}{\lambda_{i} \alpha_{i}} \\ -\lambda_{i} \alpha_{i} \sin \alpha_{i}(x-s) & \cos \alpha_{i}(x-s)\end{array}\right)$, where $\alpha_{i}=\omega \sqrt{\frac{m_{i}}{\lambda_{i}}}$.

Let's define

$$
\widetilde{B}\left(x_{n}, x_{0}, \omega\right) \stackrel{\text { def }}{=}\left(\begin{array}{ll}
b_{11}(\omega) & b_{12}(\omega) \\
b_{21}(\omega) & b_{22}(\omega)
\end{array}\right) .
$$

The nontrivial solution $\bar{X}(x, \omega)$ of the system (35) can be found as $\bar{X}(x, \omega)=\widetilde{B}\left(x, x_{0}, \omega\right) \cdot \bar{C}$, where $\bar{C}=\left(\begin{array}{l}C_{1} \\ C_{2}\end{array}\right)$ is some nonzero vector.

The vector function $\bar{X}(x, \omega)$ has to fulfill the boundary conditions (37). That is

$$
\left[P \cdot \widetilde{B}\left(x_{0}, x_{0}, \omega\right)+Q \cdot \widetilde{B}\left(x_{n}, x_{0}, \omega\right)\right] \cdot \bar{C}=\overline{0},
$$

taking into consideration that $\widetilde{B}\left(x_{0}, x_{0}, \omega\right)=E$, the following equation is received

$$
\left[P+Q \cdot \widetilde{B}\left(x_{n}, x_{0}, \omega\right)\right] \cdot \bar{C}=\overline{0} .
$$

In order for the nonzero vector $\bar{C}$ to exist the validity of the following condition is necessary and sufficient

$$
\operatorname{det}\left[P+Q \cdot \widetilde{B}\left(x_{n}, x_{0}, \omega\right)\right]=0 .
$$

Let's concretize the left part of the characteristic equation (41), taking into consideration the matrices $P, Q$ and (39)

$$
\operatorname{det}\left[P+Q \cdot \widetilde{B}\left(x_{n}, x_{0}, \omega\right)\right]=\operatorname{det}\left[\left(\begin{array}{ll}
1 & 0 \\
0 & 0
\end{array}\right)+\left(\begin{array}{ll}
0 & 0 \\
1 & 0
\end{array}\right) \cdot\left(\begin{array}{ll}
b_{11}(\omega) & b_{12}(\omega) \\
b_{21}(\omega) & b_{22}(\omega)
\end{array}\right)\right]=
$$




$$
=\operatorname{det}\left[\left(\begin{array}{cc}
1 & 0 \\
b_{11}(\omega) & b_{12}(\omega)
\end{array}\right)\right]=b_{12}(\omega) .
$$

Let's make the following proposition.

Remark 2. Characteristic equation of the eigenvalue problem is the following

$$
b_{12}(\omega)=0
$$

As known [8], the roots $\omega_{k}$ of the characteristic equation (42), that are also eigenvalues of the problem (27), (28), are positive and different.

In order to find the nonzero vector $\bar{C}$ let's substitute $\omega_{k}$ with $\omega$ into the equation (40). Then the following vectorial equality is received

$$
\left(\begin{array}{cc}
1 & 0 \\
b_{11}\left(\omega_{k}\right) & b_{12}\left(\omega_{k}\right)
\end{array}\right) \cdot\left(\begin{array}{l}
C_{1} \\
C_{2}
\end{array}\right)=\left(\begin{array}{l}
0 \\
0
\end{array}\right)
$$

that is equivalent to the system of equations

$$
\left\{\begin{array}{l}
C_{1}=0 \\
b_{11}\left(\omega_{k}\right) \cdot C_{1}+b_{12}\left(\omega_{k}\right) \cdot C_{2}=0
\end{array}\right.
$$

Since the determinant of this system $b_{12}(\omega)=0$, then the system (43) has the following solutions $C_{1}=0, C_{2} \in \mathbb{R} \backslash\{0\}$. By introducing, for example $C_{2}=1$, $\bar{C}=\left(\begin{array}{l}0 \\ 1\end{array}\right)$ is received. Note, that the vector $\bar{C}$ doesn't depend on $\omega_{k}$. Let $\bar{X}_{k}\left(x, \omega_{k}\right)$ be a nontrivial eigenvector that corresponds to the value of $\omega_{k}$.

Remark 3. The eigenvectors of the system of differential equations (35) with boundary conditions (37) have the following structure

$$
\bar{X}_{k}\left(x, \omega_{k}\right)=\widetilde{B}\left(x, x_{0}, \omega_{k}\right) \cdot\left(\begin{array}{l}
0 \\
1
\end{array}\right), \quad k \in \mathbb{N} .
$$

Cosequence 1. The eigenfunctions $X_{k}\left(x, \omega_{k}\right)$ as the first coordinates of the eigenvectors $\bar{X}_{k}\left(x, \omega_{k}\right)$ can be written down as

$$
X_{k}\left(x, \omega_{k}\right)=\left(\begin{array}{ll}
1 & 0
\end{array}\right) \cdot \widetilde{B}\left(x, x_{0}, \omega_{k}\right) \cdot\left(\begin{array}{l}
0 \\
1
\end{array}\right), \quad k=1,2,3, \ldots
$$

In particular, since the $X_{k}\left(x, \omega_{k}\right)$ is $(34)$, then from (38) and (44) follows that

$$
X_{k i}\left(x, \omega_{k}\right)=\left(\begin{array}{ll}
1 & 0
\end{array}\right) \cdot \widetilde{B}_{i}\left(x, x_{i}, \omega_{k}\right) \cdot \widetilde{B}\left(x_{i}, x_{0}, \omega_{k}\right) \cdot\left(\begin{array}{l}
0 \\
1
\end{array}\right), \quad i=\overline{0, n-1}
$$


5. Building a solution to the mixed problem (22) - (24). In order to solve the problem (22) - (24) let's apply the eigenfunctions method [12], what means that the problem's solution can be found in a following form

$$
v(x, t)=\sum_{k=1}^{\infty} T_{k}(t) \cdot X_{k}\left(x, \omega_{k}\right),
$$

where $T_{k}(t)$ are unknown functions that will be later defined.

Since $\frac{\partial^{2} w}{\partial t^{2}}$ is in the right side of equation (22) let's expand it into the Fourier series by the eigenfunctions $X_{k}\left(x, \omega_{k}\right)$ of the boundary problem $(27),(28)$

$$
\frac{\partial^{2} w}{\partial t^{2}}=\sum_{k=1}^{\infty} w_{k}(t) \cdot X_{k}\left(x, \omega_{k}\right)
$$

Substituting (46) into the equation (22) and considering (47), the following equation is received

$$
\begin{gathered}
m(x) \cdot \sum_{k=1}^{\infty} T_{k}{ }^{\prime \prime}(t) \cdot X_{k}\left(x, \omega_{k}\right)=\sum_{k=1}^{\infty} T_{k}(t) \cdot\left(\lambda(x) X_{k}{ }^{\prime}\left(x, \omega_{k}\right)\right)^{\prime}- \\
-m(x) \cdot \sum_{k=1}^{\infty} w_{k}(t) \cdot X_{k}\left(x, \omega_{k}\right) .
\end{gathered}
$$

Considering that the eigenfunctions $X_{k}\left(x, \omega_{k}\right)$ satisfy the equation (27), we get an equality

$$
\begin{gathered}
m(x) \cdot \sum_{k=1}^{\infty} T_{k}^{\prime \prime}(t) \cdot X_{k}\left(x, \omega_{k}\right)=-m(x) \sum_{k=1}^{\infty} \omega_{k}^{2} \cdot X_{k}\left(x, \omega_{k}\right) T_{k}(t)- \\
-m(x) \cdot \sum_{k=1}^{\infty} w_{k}(t) \cdot X_{k}\left(x, \omega_{k}\right), \\
\sum_{k=1}^{\infty}\left[T_{k}{ }^{\prime \prime}(t)+\omega_{k}^{2} \cdot T_{k}(t)+w_{k}(t)\right] \cdot m(x) \cdot X_{k}\left(x, \omega_{k}\right)=0 .
\end{gathered}
$$

Let's multiply the right and left parts $(48)$ by $X_{j}\left(x, \omega_{j}\right)$ and integrate by the variable $x$ on the interval $\left[x_{0} ; x_{n}\right)$. Considering the eigenfunctions' orthogonality we get each of the differential equations

$$
T_{k}^{\prime \prime}(t)+\omega_{k}^{2} \cdot T_{k}(t)=-w_{k}(t), \quad k=1,2,3, \ldots
$$

The general solution of each of the differential equations (49) is

$$
T_{k}(t)=a_{k} \cos \omega_{k} t+d_{k} \sin \omega_{k} t-\frac{1}{\omega_{k}} \int_{0}^{t} \sin \omega_{k}(t-s) \cdot w_{k}(s) d s,
$$

where $a_{k}, d_{k}$ are unknown constants [3]. 
Let's declare $I(t)=\frac{1}{\omega_{k}} \int_{0}^{t} \sin \omega_{k}(t-s) \cdot w_{k}(s) d s . \quad$ Note that $I(0)=0$, $I^{\prime}{ }_{t}(0)=0[4]$.

In order to find the constants $a_{k}, d_{k}$ let's expand the right parts of the initial conditions (23) into the Fourier series by the eigenfunctions $X_{k}\left(x, \omega_{k}\right)$

$$
\begin{aligned}
& \Phi_{0}(x)=\sum_{k=1}^{\infty} \Phi_{0 k} \cdot X_{k}\left(x, \omega_{k}\right), \\
& \Phi_{1}(x)=\sum_{k=1}^{\infty} \Phi_{1 k} \cdot X_{k}\left(x, \omega_{k}\right),
\end{aligned}
$$

where $\Phi_{0 k}, \Phi_{1 k}$ are the corresponding Fourier coefficients.

From (50) follows that

$$
\begin{gathered}
T_{k}(0)=a_{k}, \\
T_{k}{ }^{\prime}(t)=-a_{k} \omega_{k} \sin \omega_{k} t+d_{k} \omega_{k} \cos \omega_{k} t-I_{t}{ }^{\prime}(t),
\end{gathered}
$$

so

$$
T_{k}{ }^{\prime}(0)=d_{k} \omega_{k} .
$$

Taking into account (46), (51) and the first condition in (23) the following is received: $\sum_{k=1}^{\infty} T_{k}(0) \cdot X_{k}\left(x, \omega_{k}\right)=\sum_{k=1}^{\infty} \Phi_{0 k} \cdot X_{k}\left(x, \omega_{k}\right)$. Now using (53) we receive

$$
T_{k}(0)=a_{k}=\Phi_{0 k} .
$$

Analogically from (46), (52) and the second condition in (23) $\sum_{k=1}^{\infty} T_{k}{ }^{\prime}(0) \cdot X_{k}\left(x, \omega_{k}\right)=\sum_{k=1}^{\infty} \Phi_{1 k} \cdot X_{k}\left(x, \omega_{k}\right)$ is received. Using (54) we find

$$
T_{k}^{\prime}(0)=d_{k} \omega_{k}=\Phi_{1 k} \text { or } d_{k}=\frac{\Phi_{1 k}}{\omega_{k}} .
$$

Thus, finally a solution of the mixed problem (22) - (24) is received in a form of the series

$$
v(x, t)=\sum_{k=1}^{\infty}\left[\Phi_{0 k} \cos \omega_{k} t+\frac{\Phi_{1 k}}{\omega_{k}} \sin \omega_{k} t-\frac{1}{\omega_{k}} \int_{0}^{t} \sin \omega_{k}(t-s) \cdot w_{k}(s) d s\right] X_{k}\left(x, \omega_{k}\right) .
$$

Considering (34) and that $v(x, t)=\sum_{i=0}^{n-1} v_{i}(x, t) \cdot \theta_{i}$, where $v_{i}(x, t)$ are defined on the interval $\left[x_{i} ; x_{i+1}\right)$, we receive

$$
\begin{gathered}
v_{i}(x, t)=\sum_{k=1}^{\infty}\left[\Phi_{0 k} \cos \omega_{k} t+\frac{\Phi_{1 k}}{\omega_{k}} \sin \omega_{k} t-\frac{1}{\omega_{k}} \int_{0}^{t} \sin \omega_{k}(t-s) \cdot w_{k}(s) d s\right] \times \\
\times X_{k i}\left(x, \omega_{k}\right),
\end{gathered}
$$


where the functions $X_{k i}\left(x, \omega_{k}\right)$ are computed by the formula (45).

Considering (21), (55) the solution of the problem (1)-(3) is received

$$
u(x, t)=\sum_{i=0}^{n-1}\left[w_{i}(x, t)+v_{i}(x, t)\right] \cdot \theta_{i} .
$$

Conclusion. The expansion by the eigenfunctions theorem is adapted for the case of differential equations with piecewise constant (by the spatial variable) coefficients.

Explicit formulas for finding the solution and its quasi-derivatives for any partial interval of the main interval that are valid for arbitrary finite numbers of the first type break points of the earlier referred coefficients are received.

This scheme of problem examination was considered in a case of rectangular Cartesian coordinate system. However, it remains valid in a case of any curvilinear orthogonal coordinates. The advantage of this method is a possibility to examine the problem on each breakdown segment and then using the matrix calculation to write down an analytical expression of the solution. Such an approach allows the use of software tools for solving the problem.

The received results have a direct application to applied problems.

1. V.Ya. Arsenin, Methods of Mathematical Physics. - Nauka, Moscow, 1974.

2. A. Halanay and D. Veksler, Qualitative Theory of Pulse Systems. - Mir, Moscow, 1971.

3. P.I. Kaleniuk, J.K. Rudavsky, R.M. Tatsij, I.F. Kliinik, V.M. Kolesnik, P.P. Kostrobij, I.Ya. Oleksiv, Differential Equations. - Lviv Polytechnic Publisher, Lviv, 2014.

4. V.S. Martynenko, Operational Calculus. - Vyshcha Shkola, Kiev, 1973.

5. V.V. Mazurenko, On the reduction of discrete- continuous boundary value problem for the generalized scheme Atkinson. - Reports of the National Academy of Sciences of Ukraine, Vol. 8 (2001), 19-22.

6. A. M. Samoilenko, N. A. Perestyuk, Impulse Differential Equations. - Vyshcha Shkola, Kiev, 1987.

7. R.M. Tatsij, O.Yu. Chmyr, O.O. Karabyn, The total boundary value problems for hiperbolic equation with piecewise continuous coeffitients and right parts. - Researches in mathematics and mechanics, Vol. 22 (2017), No. 2(30), 55-70.

8. R.M. Tatsij, V.V. Mazurenko, Discrete-continuous boundary problems for the quasi-differential equations of even order. - Mathematical Methods and PhysicoMechanical Fields, Vol. 44 (2001), No. 1, 43-53.

9. R.M. Tatsij, M.F. Stasjuk, V.V. Mazurenko, O.O. Vlasij, Generalized Quasidifferential Equations. - Kolo, Drogobych, 2011.

10. R.M. Tatsij, M.F. Stasjuk, O.O. Vlasij, Discrete-continuous boundary problems for the quasi-differential equations of second order. - Bulletin of the University "Lviv Polytechnic", series "Physics and mathematics", Vol. 718 (2011), 61-69. 
11. R.M. Tatsij, O.O. Vlasij, M.F. Stasjuk, General first boundary value problem for the heat equation with piecewise variable coefficients. - Bulletin of the University "Lviv Polytechnic", series "Physics and mathematics", Vol. 804 (2014), 64-69.

12. A.N. Tikhonov, A.A. Samarskii, Equations of Mathematicai Physics. - Nauka, Moscow, 1977.

13. O.O. Vlasij, M.F. Stasjuk, R.M. Tatsij, The structure of generalized solutions of systems with piecewise variable coefficients. - Bulletin of the University "Lviv Polytechnic", series "Physics and mathematics", Vol. 660 (2009), 34-38.

Тацій Р. М., Чмир О. Ю., Карабин О. О.

ПЕРША ДИСКРЕТНО-НЕПЕРЕРВНА КРАЙОВА ЗАДАЧА ДЛЯ РІВНЯННЯ ГІПЕРБОЛІЧНОГО ТИПУ З КУСКОВО - СТАЛИМИ КОЕФІЦІЕНТАМИ ТА $\delta$-ОСОБЛИВОСТЯМИ

Резюме

Вперше запропоновано та обгрунтовано нову формальну схему розв'язування загальної першої крайової задачі для рівняння гіперболічного типу з кусково-сталими коефіцієнтами та $\delta$-особливостями. В основу схеми розв'язування покладено концепцію квазіпохідних, сучасну теорію систем лінійних диференціальних рівнянь, а також класичний метод Фур'є та метод редукції. Перевагою методу є можливість розглянути задачу на кожному відрізку розбиття, а потім за допомогою матричного числення записати аналітичний вираз розв'язку. Такий підхід дозволяе застосовувати програмні засоби до процесу вирішення задачі та графічної ілюстрації розв'язку.

Ключові слова: квазідиферениіалъне рівняння, крайова задача, матриця Коші, функція Дірака, задача на власні значення, метод Фур'є та метод власних функиій .

Таций Р.М., Чмыръ О.Ю., Карабин О.О.

ПЕРВАЯ ДИСКРЕТНО-НЕПРЕРЫВНАЯ КРАЕВАЯ ЗАДАЧА ДЛЯ УРАВНЕНИЯ ГИПЕРБОЛИЧЕСКОГО ТИПА С КУСОЧНО-ПОСТОЯННЫМИ КОЭФФИЦИЕНТАМИ И $\delta$-ОСОБЕННОСТЯМИ

Резюме

Впервые предложена и обоснована новая формальная схема решения общей первой краевой задачи для уравнения гиперболического типа с кусочно-постоянными коэффициентами и $\delta$-особенностями. В основе схемы решения лежит концепция квазипроизводных, современная теория систем линейных дифференциальных уравнений, а также классический метод Фурье и метод редукции. Преимуществом метода является возможность рассмотреть задачу на каждом отрезке разбиения, а затем на основании матричного исчисления объединить полученные решения. Такой подход позволяет применить программные средства к процессу разрешения задачи и графической иллюстрации решения.

Ключевые слова: квазидифференциальное уравнение, краевая задача, матрица Кочи, функция Дирака, задача на собственные значения, метод Фуръе и метод собственных функций .

\section{REFERENCES}

1. Arsenin, V. Ya. (1974). Metody matematicheskoyu phiziki [Methods of Mathematical Physics]. Moscow: Nauka, 432 p.

2. Halanay, A. and Veksler, D. (1971). Yakisna teoriya impulsnykh system [Qualitative Theory of Pulse Systems]. Moscow: Mir, 315 p. 
3. Kaleniuk, P. I., Rudavsky, J. K., Tatsij, R. M., Kliinik, I. F., Kostrobij, P. P., Oleksiv, I. Ya. (2014). Dyferentsialni rivnyannya [Differential Equations]. Lviv: Polytechnic Publisher, 380 p.

4. Martynenko, V. S. (1973). Operatsionnoye ischislyeniye [The operational calculus]. Kyiv: Vyshcha shkola, $359 \mathrm{p}$.

5. Mazurenko, V. V. (2001). Pro zvidnist dyskretno-neperervnoyi krayovoyi zadachi do uzagalnenoyi skhemy Atkinsona [On the reduction of discrete- continuous boundary value problem for the generalized scheme Atkinson]. Reports of the National Academy of Sciences of Ukraine, Vol. 8. - P. 19-22.

6. Samoilenko A. M., Perestyuk N. A. (1987). Impulsni dyferentsiayni rivnyannya [Impulse Differential Equations]. Kyiv: Vyshcha shkola, 472 p.

7. Tatsij R.M. , Chmyr O.Yu., Karabyn O.O. (2017) Zagalni krayovi zadachi dlya hiperbolichnogo rivnyannya iz kuskovo-neperervnymy koefitsiyentamy ta pravymy chastynamy [The total boundary value problems for hiperbolic equation with piecewise continuous coeffitients and right parts]. Researches in mathematics and mechanics, Vol. 22, No. 2(30). - P. 55-70.

8. Tatsij R.M., Mazurenko, V. V. (2001). Dyskretno-neperervni krayovi zadachi dlya kvazidyferentsialnykh rivnyan dovilnogo poryadku [Discrete-continuous boundary problems for the quasi-differential equations of even order]. Reports of the Mathematical Methods and Physico-Mechanical Fields, Vol. 44, No. 1. - P. 43-53.

9. Tatsij, R. M., Stasjuk, M. F., Mazurenko, V. V., Vlasij, O. O. (2011). Uzagalneni kvazidyferentsialni rivnyannya [Generalized quasi-differential equations]. Drogobych: Kolo, 297 p.

10. Tatsij, R. M., Vlasij, O. O., Stasjuk, M. F. (2011). Dyskretno-neperervni krayovi zadachi dlya kvazi-dyferentsialnykh rivnyan drugogo poryadku [Discrete-continuous boundary problems for the quasi-differential equations of second order]. Bulletin of the University "Lviv Polytechnic", series "Physics and mathematics", Vol. 718. - P. 61-69.

11. Tatsij, R. M., Vlasij, O. O., Stasjuk, M. F. (2014). Zagalna persha krayova zadacha dlya rivnyannya teploprovidnosti z kuskovo-zminnymy koefitsiyentamy [General first boundary value problem for the heat equation with piecewise variable coefficients]. Bulletin of the University "Lviv Polytechnic", series "Physics and mathematics", Vol. 804. - P. 64-69.

12. Tikhonov, A. N., Samarskii, A. A. (1977). Uravneniya matematicheskoyu phiziki [Equations of Mathematicai Physics]. Moscow: Nauka, 735 p.

13. Vlasij, O. O., Stasjuk, M. F., Tatsij, R. M., (2009). Struktura rozvyazkiv uzagalnenykh system z kuskovo-zminnymy koefitsiyentamy [The structure of generalized solutions of systems with piecewise variable coefficients]. Bulletin of the University "Lviv Polytechnic", series "Physics and mathematics", Vol. 660. - P. 34-38. 